\title{
Amiodarone and diffuse alveolar hemorrhage
}

To the Editor,

Amiodarone, a common anti-arrhythmic drug, is well known for its pulmonary toxicity. Pulmonary toxicity is reported to occur at a rate of $1-5 \%$, with this rate rising with an increased daily dose $>200 \mathrm{mg}$ and drug accumulation over several years. Pulmonary toxicity by amiodarone may present just few days up to several years after the initiation of the drug [1]. Most common complications are chronic interstitial pneumonitis, organizing pneumonia, eosinophilic pneumonia, pleural effusion, acute respiratory distress syndrome (ARDS) and pulmonary nodules/masses [2]. Diffuse alveolar hemorrhage (DAH) is described as a rare amiodarone-related toxicity, so far reported in the form of scarce, very few case reports. We report 2 cases of amiodarone-associated DAH in order to highlight the significance of this complication.

Our first case was a 70-year-old female who was receiving amiodarone $200 \mathrm{mg}$ per day due to supra-ventricular arrhythmias for the past 5 months. She was asymptomatic, but resting hypoxemia was noticed by her cardiologist on a regular follow-up visit, along with a new finding of pulmonary hypertension of $65 \mathrm{~mm} \mathrm{Hg}$. She had no evidence of heart failure; a high-resolution computed tomography scan (HRCT) then performed revealed ground-glass opacities distributed bilaterally in the upper and lower lung fields, along with mosaic attenuation (Figures 1A, 1B). Blood tests showed a decrease in hemoglobin levels by $1 \mathrm{~g} / \mathrm{dL}$. In bronchoalveolar lavage (BAL), $58 \%$ of alveolar macrophages were hemosiderin-laden, positive on Perls' stain. Autoimmunity testing and urine sediment were all negative. The patient responded well to $32 \mathrm{mg}$ prednisone as a starting dose. Opacities cleared after 3 months of treatment and pulmonary hypertension completely subsided.

The second case was a 54-year-old male. He received amiodarone for the past 3 weeks at a dose of $600 \mathrm{mg}$ per day to control atrial fibrillation. He complained of shortness of breath for the past 2 days and mild hemoptysis. Cardiac function was normal. HRCT scan showed hazy opacities bilaterally, ground-glass attenuation and increased interstitial markings extending at the lung periphery (Figures 1C, 1D). Hemoglobin was stable and oxygenation normal. BAL was macroscopically hemorrhagic and showed 100\% hemosiderin-laden macrophages positive on Perls' stain. He had no evidence of vasculitis or hematouria. Apart from amiodarone, he was receiving apixaban for the past 6 years; however, the latest implemented drug (amiodarone) was considered responsible for DAH in this patient. He was started on methyl-prednisolone $600 \mathrm{mg} /$ /day for 5 days and then switched to prednisone $48 \mathrm{mg} /$ day with good response.

Only seven cases of DAH due to amiodarone are reported in the literature [3-5]. In one case, diagnosis was established post-mortem, while the others responded to treatment with corticosteroids and removal of amiodarone. Reinstitution of amiodarone resulted in repeated DAH incidents. Pathogenetically, amiodarone is shown in vitro and in vivo studies responsible for interstitial pneumonitis by direct cellular cytotoxicity, accumulation of phospholipid complexes and activation of angiotensin converting enzyme leading to alveolar epithelial and macrophage cells injury and apoptosis; indirectly via an immunological

Address for correspondence: Ilias Papanikolaou, Department of Pulmonary Medicine, Corfu General Hospital, Corfu, Greece; e-mail: icpapanikolaou@hotmail.com DOI: 10.5603/ARM.2020.0095 


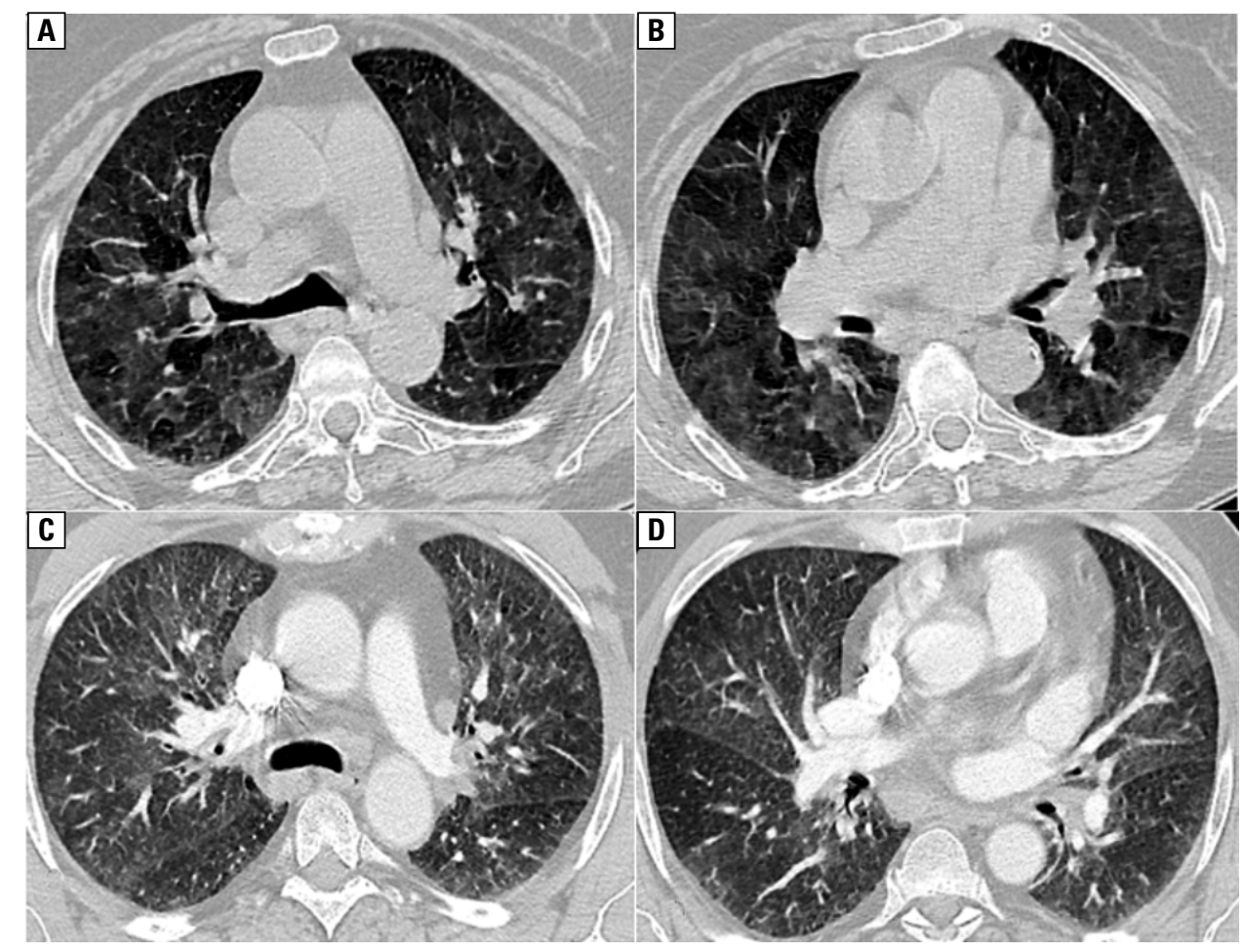

Figure 1. A, B. First case of female patient, ground glass and mosaic attenuation bilaterally; C, D. Second case of male patient, hazy ground-glass opacities located centrally bilaterally along with interstitial markings at the periphery

reaction characterized by CD8-T lymphocytosis that resembles hypersensitivity pneumonitis [6, 7]. In the case of amiodarone causing $\mathrm{DAH}$, the underlying mechanism responsible is diffuse alveolar damage (DAD) [8]. DAD pathology associates either with ARDS or with DAH and is characterized by alveolar septa edema and hyaline membranes formation.

DAH in a patient receiving amiodarone who presents with symptoms or new radiology findings has to be differentiated from cardiogenic diseases and from the rest of amiodarone pulmonary toxicities. This is based on radiology and pulmonary function tests. Pulmonary function tests in DAH will not exhibit significant restriction, while diffusing capacity instead of decreased is found normal or increased. HRCT is characterized by ground-glass attenuation and mosaic pattern in adjacent normal lung tissue [9]. Diagnosis is established by BAL, which typically demonstrates hemosiderin-laden macrophages $>20 \%$ of total macrophages on Perls' Prussian Blue stain [10]. Lung biopsy is not required for the diagnosis of DAH. Both cases cases we present in this study had typical HRCT and BAL features.

Treatment strategies for amiodarone interstitial pneumonitis or DAH are based solely on case series. While for the former, drug removal and/or prednisone $0.5 \mathrm{mg} / \mathrm{kg}$ are proposed, it is possible that for the latter, pulse corticosteroids are required, as in other DAH etiologies.

In conclusion, as illustrated in our study, DAH due to amiodarone may not be as rare as it is believed. Since HRCT is not diagnostic, BAL should be performed to differentiate from other amiodarone-related or other disorders. Awareness is mandatory to quickly remove amiodarone and initiate corticosteroids.

\section{Conflict of interest}

None declared.

\section{References:}

1. Camus P. Interstitial lung disease from drugs, biologics, and radiation. In: Schwartz MI, King TE Jr (ed.). Interstitial lung disease. 5th ed. Peole's Medical Publishing House, Shelton, CT 2011: 637.

2. Papiris SA, Triantafillidou C, Kolilekas L, et al. Amiodarone: review of pulmonary effects and toxicity. Drug Saf. 2010; 33(7): 539-558, doi: 10.2165/11532320-000000000-00000, indexed in Pubmed: 20553056.

3. Tanawuttiwat T, Harindhanavudhi T, Hanif S, et al. Amiodarone-induced alveolar haemorrhage: a rare complication of a common medication. Heart Lung Circ. 2010; 19(7): 435-437, doi: 10.1016/j.hlc.2010.01.008, indexed in Pubmed: 20356785.

4. Borders CW, Bennett S, Mount C, et al. A rare case of acute diffuse alveolar hemorrhage following initiation of amiodarone: a case report. Mil Med. 2012; 177(1): 118-120, doi: 10.7205/ milmed-d-11-00208, indexed in Pubmed: 22338993. 
5. Saeed J, Waqas QA, Khan UI, et al. Amiodarone-induced diffuse alveolar haemorrhage: a rare but potentially life-threatening complication of a commonly prescribed medication. BMJ Case Rep. 2019; 12(10), doi: 10.1136/bcr-2019-232149, indexed in Pubmed: 31653638.

6. Kosseifi SG, Halawa A, Halawa A, et al. Reduction of amiodarone pulmonary toxicity in patients treated with angiotensin-converting enzyme inhibitors and angiotensin receptor blockers. Ther Adv Respir Dis. 2009; 3(6): 289-294, doi: 10.1177/1753465809348015, indexed in Pubmed: 19850648.

7. Akoun GM, Gauthier-Rahman S, Milleron BJ, et al. Amiodarone-induced hypersensitivity pneumonitis. Evidence of an immunological cell-mediated mechanism. Chest. 1984; 85(1): 133-135, doi: 10.1378/chest.85.1.133, indexed in Pubmed: 6606534.
8. Spira D, Wirths S, Skowronski F, et al. Diffuse alveolar hemorrhage in patients with hematological malignancies: HRCT patterns of pulmonary involvement and disease course. Clin Imaging. 2013; 37(4): 680-686, doi: 10.1016/j.clinimag.2012.11.005, indexed in Pubmed: 23313188.

9. Worthy SA, Müller NL, Hartman TE, et al. Mosaic attenuation pattern on thin-section CT scans of the lung: differentiation among infiltrative lung, airway, and vascular diseases as a cause. Radiology. 1997; 205(2): 465-470, doi: 10.1148/radiology.205.2.9356630, indexed in Pubmed: 9356630.

10. De Lassence A, Fleury-Feith J, Escudier E, et al. Alveolar hemorrhage. Diagnostic criteria and results in 194 immunocompromised hosts. Am J Respir Crit Care Med. 1995; 151(1): 157-163, doi: 10.1164/ajrccm.151.1.7812547, indexed in Pubmed: 7812547. 